NASA/TM-2003-212513

\title{
On-Orbit Performance Degradation of the International Space Station P6 Photovoltaic Arrays
}

Thomas W. Kerslake and Eric D. Gustafson

Glenn Research Center, Cleveland, Ohio 
Since its founding, NASA has been dedicated to the advancement of aeronautics and space science. The NASA Scientific and Technical Information (STI) Program Office plays a key part in helping NASA maintain this important role.

The NASA STI Program Office is operated by Langley Research Center, the Lead Center for NASA's scientific and technical information. The NASA STI Program Office provides access to the NASA STI Database, the largest collection of aeronautical and space science STI in the world. The Program Office is also NASA's institutional mechanism for disseminating the results of its research and development activities. These results are published by NASA in the NASA STI Report Series, which includes the following report types:

- $\quad$ TECHNICAL PUBLICATION. Reports of completed research or a major significant phase of research that present the results of NASA programs and include extensive data or theoretical analysis. Includes compilations of significant scientific and technical data and information deemed to be of continuing reference value. NASA's counterpart of peerreviewed formal professional papers but has less stringent limitations on manuscript length and extent of graphic presentations.

- TECHNICAL MEMORANDUM. Scientific and technical findings that are preliminary or of specialized interest, e.g., quick release reports, working papers, and bibliographies that contain minimal annotation. Does not contain extensive analysis.

- CONTRACTOR REPORT. Scientific and technical findings by NASA-sponsored contractors and grantees.
- CONFERENCE PUBLICATION. Collected papers from scientific and technical conferences, symposia, seminars, or other meetings sponsored or cosponsored by NASA.

- SPECIAL PUBLICATION. Scientific, technical, or historical information from NASA programs, projects, and missions, often concerned with subjects having substantial public interest.

- TECHNICAL TRANSLATION. Englishlanguage translations of foreign scientific and technical material pertinent to NASA's mission.

Specialized services that complement the STI Program Office's diverse offerings include creating custom thesauri, building customized databases, organizing and publishing research results ... even providing videos.

For more information about the NASA STI Program Office, see the following:

- Access the NASA STI Program Home Page at http://www.sti.nasa.gov

- E-mail your question via the Internet to help@sti.nasa.gov

- Fax your question to the NASA Access Help Desk at 301-621-0134

- Telephone the NASA Access Help Desk at 301-621-0390

- Write to:

NASA Access Help Desk

NASA Center for AeroSpace Information 7121 Standard Drive

Hanover, MD 21076 
NASA/TM-2003-212513

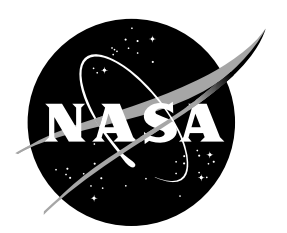

\section{On-Orbit Performance Degradation of the International Space Station P6 Photovoltaic Arrays}

Thomas W. Kerslake and Eric D. Gustafson

Glenn Research Center, Cleveland, Ohio

Prepared for the

First International Energy Conversion Engineering Conference cosponsored by the American Institute of Aeronautics and Astronautics (AIAA), the American Society of Mechanical Engineers (ASME), and the Institute of Electrical and Electronics Engineers (IEEE) Portsmouth, Virginia, August 17-21, 2003

National Aeronautics and

Space Administration

Glenn Research Center 


\section{Acknowledgments}

The authors wish to acknowledge Jeff Hojnicki of NASA Glenn Research Center for providing technical expertise on many different facets of ISS power system design and performance.

This report is a formal draft or working paper, intended to solicit comments and ideas from a technical peer group.

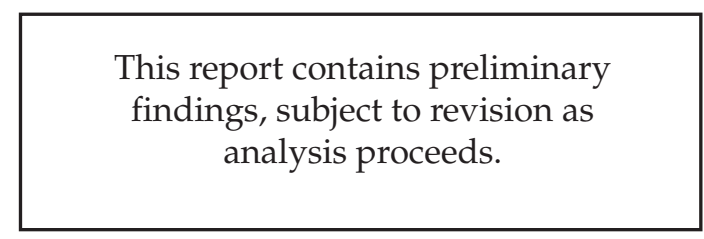

Available from

NASA Center for Aerospace Information 7121 Standard Drive

Hanover, MD 21076
National Technical Information Service 5285 Port Royal Road Springfield, VA 22100 


\title{
ON-ORBIT PERFORMANCE DEGRADATION OF THE INTERNATIONAL SPACE STATION P6 PHOTOVOLTAIC ARRAYS
}

\author{
Thomas W. Kerslake ${ }^{1}$ and Eric D. Gustafson ${ }^{2}$ \\ National Aeronautics and Space Administration \\ Glenn Research Center \\ Cleveland, Ohio 44135
}

\begin{abstract}
This paper discusses the on-orbit performance and performance degradation of the International Space Station P6 solar array wings (SAWs) from the period of December 2000 through February 2003. Data selection considerations and data reduction methods are reviewed along with the approach for calculating array performance degradation based on measured string shunt current levels. Measured degradation rates are compared with those predicted by the computational tool "SPACE" and prior degradation rates measured with the same SAW technology on the Mir space station. Initial results show that the measured SAW short-circuit current is degrading $0.2 \%-0.5 \%$ per year. This degradation rate is below the predicted rate of $0.8 \%$ per year and is well within the $\pm 3 \%$ estimated uncertainty in measured SAW current levels. General contributors to SAW degradation are briefly discussed.
\end{abstract}

\section{Introduction}

The P6 solar power module (SPM), shown in Figure 1, was launched and installed on the International Space Station (ISS) in December 2000 and has continued to reliably meet ISS power loads. SPM power is generated by a photovoltaic array comprised of two solar array wings (SAWs). Each SAW has two flexible blankets populated with $8 \mathrm{~cm}$ by $8 \mathrm{~cm}$, crystalline silicon solar cells. To achieve a nominal $160-\mathrm{V}$ operating voltage, 400 solar cells are series connected to form a string. There are 82 solar cell strings on each SAW. SAW voltage is regulated by a sequential shunt unit SSU) that also contains sensors to measure SAW output current, shunt current, number of shunted strings and selected string voltages. However,
SAW temperatures are not measured. The data are telemetered to the ground and processed in the Orbiter Data Reduction Center (ODRC) for subsequent retrieval and analysis. Since P6 activation, the electrical performance of these SAWs has been monitored. SAW electrical performance is affected by operating parameters, such as ISS flight mode, SAW pointing, and seasonal variations in environmental heating, as well as by environmental degradation. SAW performance degradation mechanisms include solar cell proton/electron radiation damage, contamination, meteoroid/debris impact damage and optical property deterioration (i.e., from UV darkening and plasma sputtering). Open-circuited strings and failed (short-circuited) by-pass diodes also degrade SAW performance.

In the following sections, we will discuss the onorbit performance and performance degradation of the P6 SAWs from the period of December 2000 through February 2003. Data selection considerations and data reduction methods will be reviewed along with the approach for calculating array performance degradation based on measured string shunt current levels. Measured degradation rates will be compared with those predicted by the computational tool "SPACE" and prior degradation rates measured with the same SAW technology on the Mir space station.

\section{Measuring SAW Performance Degradation}

With the available output current, shunt current and string voltage telemetry, there are three primary methods to determine SAW performance degradation: (1) short-circuit (Isc), (2) operating current and (3) maximum power point current-voltage-power.

\footnotetext{
${ }^{1}$ Phone: 216-433-5373; Fax: 216-433-2995; E-mail: Thomas.W.Kerslake@nasa.gov

2Phone: 216-433-3238; Fax: 216-433-2995; E-mail: Eric.D.Gustafson@nasa.gov
} 


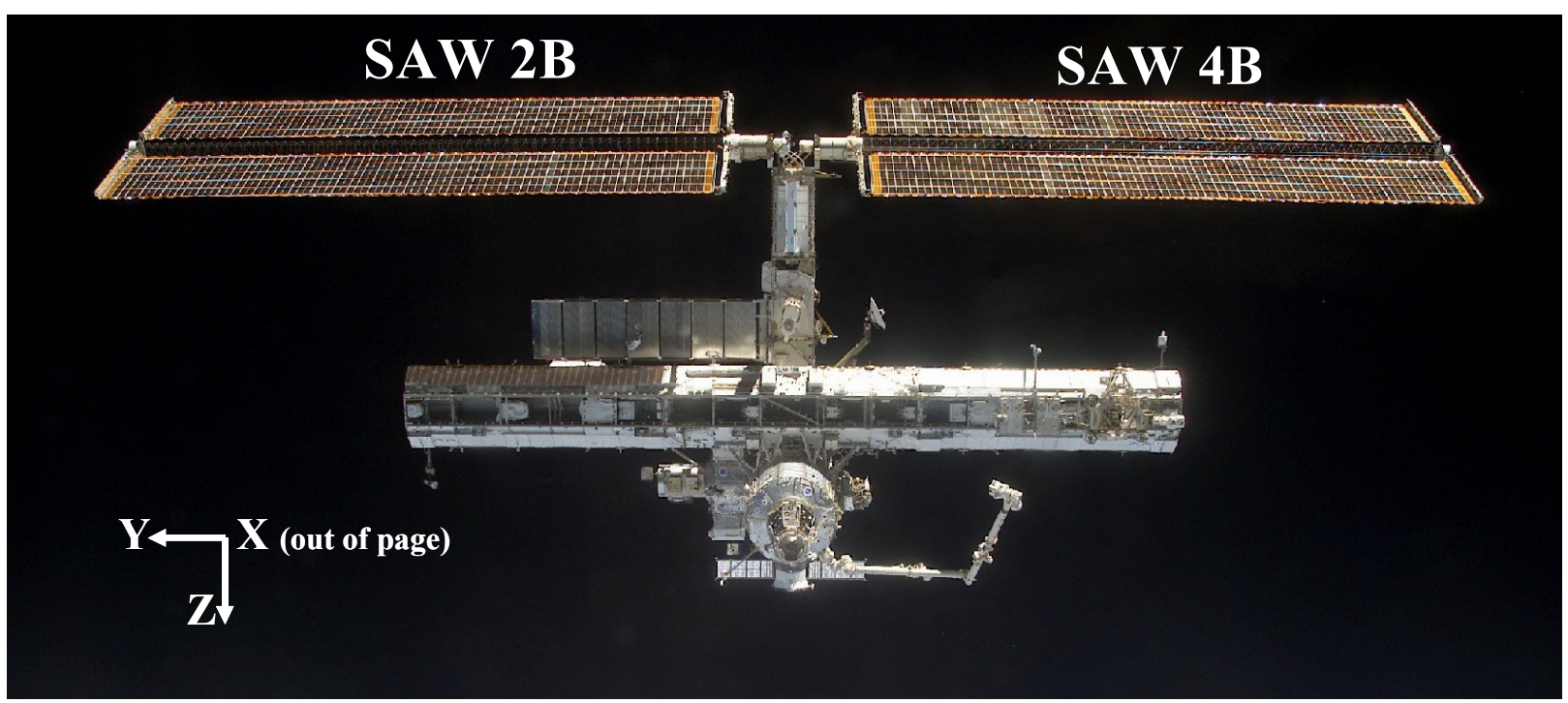

Figure 1. Photograph of the International Space Station, 11A Configuration, Taken in December 2002.

The Isc measurement approach is the cleanest approach since it is based on a direct measurement of SSU shunt current. Shunt current is not dependent on SAW operating voltage and has moderately low temperature dependency. A portion of SAW strings are generally shunted making data always available and shunt current data are less sensitive to uncertainties in computationally derived data corrections. Based on these advantages, the Isc approach was selected as the measure of SAW performance for the present work. The details of data selection and reduction for this approach are provided in the next section. The disadvantages of this approach are the expected Isc degradation rate, about $0.8 \%$ per year, is small (and thus, hard to measure) and Isc is not the primary SAW performance parameter of interest.

The primary SAW parameter of interest is operating current since this provides the best measure of operating SAW power capability. At a rate of $1.8 \%$ per year, the expected operating current degradation rate is larger than that of Isc and therefore, easier to measure. The operating SAW current data are generally available, but are more sensitive to computationally derived temperature corrections (compared to Isc data). Thus, uncertainties in calculated temperatures (note, SAW temperatures are not measured) result in larger uncertainties in corrected current data. More complex data reduction is also needed since operating current is a function of SAW operating voltage. The SAW operating voltage changes depending on SSU operating voltage set point, SSU droop (function of load) and bus regulation mode (SSU control or battery charge discharge unit control). Thus, in addition to temperature and illumination corrections, the operating current data must be sorted into operating voltage bins.
Over time, comparisons in operating current level for a given voltage bin(s) would be made to ascertain SAW degradation. This operating current approach does create a trade-off between the selected voltage bin size and the resulting data accuracy/precision and quantity of data points.

The last and most complex approach is to measure the operating current over a predetermined, wider operating voltage range to derive SAW maximum power point performance. This would be achieved by sequentially up-linking 3 to $5 \mathrm{SSU}$ voltage set point values and collecting SAW performance data for several orbits at each set point. The operating current data would be corrected and averaged at each voltage set point value. These corrected data would then be fit to a current-voltage function that can be differentiated to determine the maximum power point. This approach has the advantage of measuring the degradation of both current and voltage parameters of primary interest to SAW performance. But the approach is operationally intensive to implement and requires the most data reduction. The expected degradation rates for SAW maximum power point current, voltage and power are $1.8 \%$ per year, $1 \%$ per year and $2.7 \%$ per year, respectively.

\section{Data Selection and Reduction}

\section{Selection}

In order for a valid analysis to be performed based on the on-orbit data, there were three basic requirements that the data had to meet. The first was array shadowing. There could not be any shadowing on the array during the entire orbit. Second, the arrays had to be pointed closely at the Sun to minimize error when 
correcting for array off-pointing. Third, there had to be very few data dropouts to ensure that an average over the orbit would be accurate.

Another factor considered was the desire to have a high number of strings shunted during the orbit. This was not an issue, however, for unshadowed, Suntracking P6 SAWs in the early phase of their operational life times. In this case, the SAWs produced more power than was needed to charge relatively fresh batteries and to satisfy the relatively low channel load demand in the early ISS assembly phase. This resulted in a satisfactorily high number of shunted strings.

The selected orbits used to reduce SAW performance data are shown in Table 1 . In this table, "orbit beta angle" is the angle between the orbit plane and EarthSun line. The ISS Yaw-Pitch-Roll angles are referenced to the ISS $(0,0,0)$ base flight attitudes: (a) XvvZnadir, an Earth inertial flight attitude with the ISS $\mathrm{X}$-axis aligned with the velocity vector and $\mathrm{z}$-axis directed nadir or (b) XPOP, a solar inertial flight attitude with the ISS $\mathrm{x}$-axis perpendicular to the orbit plane. Note that for the XPOP solar inertial flight mode, a SAW locked at the correct angle can achieve good Sun pointing. Solar insolation is given normalized to the equinox insolation level and "Orbiter Docking Status" refers to the presence (mated) or absence (unmated) of the space shuttle orbiter at the ISS.

\begin{tabular}{|c|c|c|c|r|r|r|c|c|c|c|}
\hline & $\begin{array}{c}\text { Day } \\
\text { of } \\
\text { Year }\end{array}$ & $\begin{array}{c}\text { Days Since } \\
\text { Deployment }\end{array}$ & $\begin{array}{c}\text { ISS Orbit } \\
\text { Beta } \\
\text { Angle, }\end{array}$ & $\begin{array}{c}\text { ISS } \\
\text { Yaw, } \\
0^{2}\end{array}$ & $\begin{array}{c}\text { ISS } \\
\text { Pitch, } \\
0\end{array}$ & $\begin{array}{c}\text { ISS } \\
\text { Roll, } \\
0\end{array}$ & $\begin{array}{c}\text { Normalized } \\
\text { Solar } \\
\text { Insolation }\end{array}$ & $\begin{array}{c}\text { SAW } \\
\text { Articulation }\end{array}$ & $\begin{array}{c}\text { ISS Flight } \\
\text { Attitude }\end{array}$ & $\begin{array}{c}\text { Orbiter } \\
\text { Docking } \\
\text { Status }\end{array}$ \\
\hline 2001 & 46 & 74 & 4.3 & -5.0 & 10.0 & 0.0 & 1.025 & tracking & XvVZnadir & mated \\
\hline 2001 & 113 & 141 & -10.4 & 5.0 & 25.0 & 1.7 & 0.989 & tracking & XvVZnadir & mated \\
\hline 2001 & 160 & 188 & 52.1 & -3.0 & -3.0 & 0.0 & 0.970 & locked & XPOP & unmated \\
\hline 2001 & 205 & 233 & 47.2 & 0.0 & 0.0 & 0.0 & 0.969 & tracking & XPOP & unmated \\
\hline 2001 & 242 & 270 & -42.3 & -2.0 & -3.0 & 0.0 & 0.981 & tracking & XPOP & unmated \\
\hline 2001 & 269 & 297 & 43.8 & -1.0 & -3.0 & 0.0 & 0.995 & tracking & XPOP & unmated \\
\hline 2001 & 296 & 324 & -43.0 & 0.0 & -3.0 & 0.0 & 1.010 & locked & XPOP & unmated \\
\hline 2001 & 344 & 372 & 2.9 & -1.1 & 22.1 & -0.6 & 1.031 & tracking & XvVZnadir & mated \\
\hline 2002 & 6 & 399 & -41.3 & -1.0 & -3.0 & 0.0 & 1.034 & tracking & XPOP & unmated \\
\hline 2002 & 50 & 443 & -42.3 & -2.0 & -2.0 & 0.0 & 1.023 & tracking & XPOP & unmated \\
\hline 2002 & 105 & 498 & -3.9 & 0.5 & 23.2 & -0.1 & 0.993 & tracking & XvZZnadir & mated \\
\hline 2002 & 137 & 530 & 35.0 & -7.0 & 1.2 & 0.0 & 0.978 & tracking & XPOP & unmated \\
\hline 2002 & 156 & 549 & 43.4 & -1.0 & -3.0 & 0.0 & 0.971 & tracking & XPOP & unmated \\
\hline 2002 & 197 & 590 & 35.7 & -1.5 & 0.6 & 0.0 & 0.968 & tracking & XPOP & unmated \\
\hline 2002 & 239 & 632 & -40.3 & -2.0 & -2.1 & 0.0 & 0.98 & tracking & XPOP & unmated \\
\hline 2002 & 291 & 684 & -44.8 & -2.0 & -2.0 & 0.0 & 1.007 & tracking & XPOP & unmated \\
\hline 2002 & 349 & 742 & -44.6 & -1.8 & -2.0 & 0.0 & 1.032 & tracking & XPOP & unmated \\
\hline 2003 & 59 & 817 & -37.0 & -2.0 & -2.0 & 0.0 & 1.019 & tracking & XPOP & unmated \\
\hline
\end{tabular}

Table 1. Orbits Selected For Data Reduction

\section{$\underline{\text { Reduction }}$}

After the data were collected, the string Isc was calculated. Isc is the ratio of the total shunt current divided by the number of shunted strings. However, there are several factors that affect Isc, and therefore need to be corrected for a proper comparison over time. These factors (solar flux, array off-pointing, Earth albedo, and array temperature) change from orbit to orbit and even within the orbit. The correction factors for solar flux and array off-pointing can be calculated from on-orbit telemetry. However, there are no onorbit sensors to measure Earth albedo (i.e., reflected sunlight) and array temperature. These correction factors were calculated using the validated computer code SPACE (Delleur and Kerslake, 2002). SPACE is a tool developed to model the ISS Electric Power
System (EPS) and has been shown to be very accurate (Jannette, et al., 2002). The four factors used to correct the data are:

* Solar flux $(F L U X)$ - adjusts for variation of solar insolation throughout the year. FLUX is the fraction of average insolation during the year (varies deterministically by about $\pm 3 \%$; normalize to 1.0 ),

* Off-pointing (POINT) - adjusts for conditions where arrays may be off-pointed by a few degrees. POINT is the cosine of the angle between the sun vector and a vector normal to the array surface, i.e., equals 1.0 for perfect Sun pointing and 0.5 for $60^{\circ}$ off-pointed from the Sun (normalize to a perfect Sun pointing value of $1.0)$, 
* Earth albedo correction ( $A L B E D O)$ - adjusts for front and backside Earth albedo. $A L B E D O$ is the ratio of shunt current due to front side illumination over the total shunt current including current due to Earth albedo. (Normalize to no albedo current contribution),

* Array temperature (TEMP) - adjusts for the changing array temperature through the orbit (normalize to $28^{\circ} \mathrm{C}$ ).

The measured shunt current data must generally be converted to short-circuit (Isc) data by applying correction factors. These factors account for currentvoltage operating point (a shunted string operates at a finite voltage to make up for line voltage drops), operating temperature (a shunted string operates about $5^{\circ} \mathrm{C}$ hotter than an operational string), parasitic plasma current collection (an operational string collects a small amount of electron current while a shunted string essentially collects no plasma electron current) and SAW string shadowing (affects shunted string currentvoltage operating point). In this situation, the correction factors nearly offset each other while the SAW shadowing effects were avoided by selecting shadow-free orbits for data reduction. Thus, for this data reduction exercise, the measured shunt current is treated as short-circuit current.

The data is then normalized at each time step using the following formula:

$\mathrm{Isc}_{\text {normalized }}=\frac{\mathrm{Isc}_{\text {telemetry }} \cdot A L B E D O}{F L U X \cdot P O I N T}-\mathrm{AISC} \cdot\left(T E M P-28^{\circ} \mathrm{C}\right)$

where AISC is the solar cell short-circuit current temperature coefficient and Isc is the short-circuit current per string obtained by dividing the measured total shunt current by the measured number of shunted strings. The normalized Isc is then integrated over the orbit to produce a time averaged value for Isc.

The uncertainty in normalized short-circuit current per string is from three sources. The first source is inaccuracy of the SSU shunt current sensors and SSU local data interface signal conditioning / analog-todigital conversion. The specification value for this inaccuracy is $\pm 2.4 \%$ of full scale (110 amps). However, the inaccuracy was greatly reduced to $\pm 0.2 \%$ of full scale by applying a calibration curve derived from SSU ground test data using accurate current sensors (Fincannon, 2002).

The second source of uncertainty is the measured number of shunted strings. The SSU control electronics generate of voltage signal to control firing of the shunt electronics and thus, a linear relationship was specified between control voltage and number of shunted strings.
The actual voltage versus shunted strings curve is different from that specified due to different line voltage drops between the voltage signal generator and each shunt module. Thus, a "best-fit voltage versus shunted strings curve" was derived from measured SSU output and shunt (integrated) current data taken on April 1, 2001 (method from Whalen, 2002). This bestfit curve has an estimated accuracy (uncertainty) of $\pm 3 \%$.

The third and last source of uncertainty is the SPACE-generated Isc data correction factors listed above, particularly factor (3) albedo current and factor (4) array temperature. The uncertainty in SPACE array current predictions from computational methods and short-term variations in Earth albedo and infrared emission, is $\pm 6 \%$ while the uncertainty in predicted temperature is $\pm 5^{\circ} \mathrm{C}$ (Delleur and Kerslake, 2002). Taken together, these two uncertainties lead to a $\pm 1.1 \%$

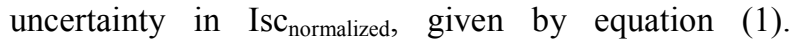
Therefore, the root-sum squared combined uncertainty in normalized short-circuit current per string from all three sources is $\pm 3.2 \%$.

\section{Results and Discussion}

Figure 2 shows the SAW Isc per string determined for wings $2 \mathrm{~B}$ and $4 \mathrm{~B}$ on the $\mathrm{P} 6$ power module over the 26-month period from wing deployment, in December 2000, until February 2003. Tabular data are provided in Table 2 below.

\begin{tabular}{|c|c|c|c|c|}
\hline \multirow[b]{2}{*}{ Year } & \multirow{2}{*}{$\begin{array}{l}\text { Day } \\
\text { of } \\
\text { Year }\end{array}$} & \multirow{2}{*}{$\begin{array}{l}\text { Days Since } \\
\text { Deployment }\end{array}$} & \multicolumn{2}{|c|}{ Isc(cna), Amps } \\
\hline & & & $2 B$ & $4 \mathrm{~B}$ \\
\hline 2001 & 46 & 74 & 2.63 & 2.64 \\
\hline 2001 & 113 & 141 & 2.65 & 2.67 \\
\hline 2001 & 160 & 188 & 2.67 & 2.66 \\
\hline 2001 & 205 & 233 & 2.66 & 2.66 \\
\hline 2001 & 242 & 270 & 2.67 & 2.67 \\
\hline 2001 & 269 & 297 & 2.67 & 2.68 \\
\hline 2001 & 296 & 324 & 2.68 & 2.67 \\
\hline 2001 & 344 & 372 & 2.65 & 2.61 \\
\hline 2002 & 6 & 399 & 2.61 & 2.62 \\
\hline 2002 & 50 & 443 & 2.65 & 2.65 \\
\hline 2002 & 105 & 498 & 2.60 & 2.64 \\
\hline 2002 & 137 & 530 & 2.61 & 2.62 \\
\hline 2002 & 156 & 549 & 2.62 & 2.64 \\
\hline 2002 & 197 & 590 & 2.65 & 2.67 \\
\hline 2002 & 239 & 632 & 2.65 & 2.66 \\
\hline 2002 & 291 & 684 & 2.64 & 2.64 \\
\hline 2002 & 349 & 742 & 2.66 & 2.67 \\
\hline 2003 & 59 & 817 & 2.63 & 2.65 \\
\hline
\end{tabular}

Table 2. SAW Isc per String Values 
These data represent orbit-Sun-period averaged, values normalized to $28^{\circ} \mathrm{C}, 1$-Sun illumination, without Earth albedo contributions. Figure 2 data points are shown with $\pm 3 \%$ error bars to reflect data uncertainties discussed above. Using linear regression, the $2 \mathrm{~B}$ and $4 \mathrm{~B}$ data were fit to lines also shown in Figure 2. Based on this best fit, the measured Isc degradation rate is $0.45 \%$ per year for $2 \mathrm{~B}$ and $0.15 \%$ per year for $4 \mathrm{~B}$. These degradation rates are consistent with and even lower than the $0.80 \%$ per year Isc degradation rate calculated by SPACE and shown as a dashed line for comparison in Figure 2. The Isc data points at day 0 were obtained from ground-based acceptance testing using Large Area Pulsed Solar Simulator test equipment and are shown for reference. The first orbital data points reduced were from February 2001 after the US laboratory module "Destiny" was installed on ISS. Destiny contained Guidance, Navigation and Control computers that provided precise ISS flight attitude and SAW position telemetry. These data were needed to accurately assess SAW Sun-pointing and shadowing conditions and compute SAW electrical performance parameters using SPACE. The measured Isc degradation and data scatter are well within the $\pm 3 \%$ data uncertainty. This suggests the sources of data errors and variations are random and tend to cancel when averaged over the orbit Sun period.

It is challenging to definitively identify a single string open-circuit failure using data sets of SAW operating current or shunt current. If a string fails open, the SSU will simply unshunt the next string in the firing sequence to supply the required current level. The calculated current per string would decrease a few percent, a value small enough that it could be lost in background data scatter. Additionally, for Isc current degradation method, data is obtained mostly for strings late in the shunt module firing order (order in which strings are unshunted). Thus, if the failed string is one of the last stings to be shunted, its failure would likely go undetected. This in fact has occurred with the $2 \mathrm{~B}$ SAW. In May 2002, the string 5 voltage sensor gave a null reading indicating a string open-circuit failure

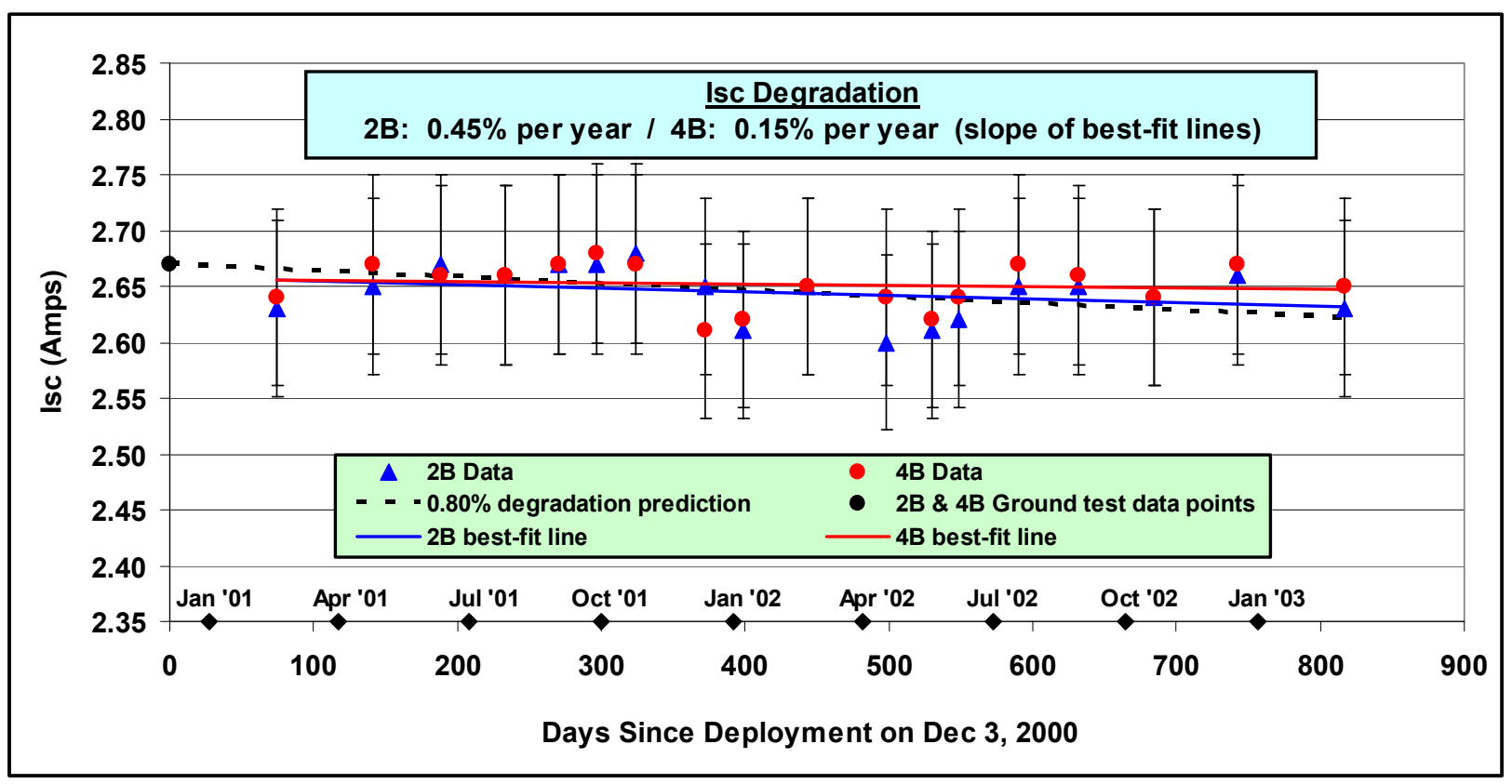

Figure 2. SAW Performance Degradation

or a sensor failure (Whalen 2002). A subsequent 2B SAW blanket photo survey revealed a delamination in the string 5 turn-around copper circuit and confirmed the source of the string open-circuit failure. String 5 is the $5^{\text {th }}$ string to turn on (or the $77^{\text {th }}$ string to be shunted) so it rarely (if ever) contributed to the shunt current measured. Hence, its failure would not be detected using the Isc method. The fact this string 5 failure was detected was somewhat fortuitous since it was one of only 22 strings instrumented with voltage sensors out of the total 82 strings.

The same photovoltaic solar cell blanket technology was successfully employed on the Mir Cooperative Solar Array (MCSA). Over the 2 $\frac{1}{2}$ year period from June 1996 and December 1998, the MCSA operating current (not Isc) degraded $3.7 \%$ per year (Kerslake and Hoffman, 1999). This value is lower than the predicted degradation rate of $4.5 \%$ per year but more than twice as high as that predicted for 
ISS SAWs. The MCSA current degradation was greater than that of ISS SAWs since the strings were operated at voltages greater than the maximum power point voltage. In this operating regime, the slope of the array current-voltage curve is large and current degradation is very sensitive to voltage loss.

\section{Causes of Degradation}

The observed Isc degradation is very small and there are no data to suggest that any particular degradation mechanism is chiefly at work. Thus, the small Isc degradation is likely attributed to the combination of degradation sources. These include optical property changes from contamination, ultraviolet light exposure, proton/electron radiation exposure and plasma sputtering that decrease solar transmittance of materials around the solar cell and increase solar absorptance leading to higher solar cell operating temperature and lower voltage output. Proton/electron irradiation damages the solar cell crystal lattice, increasing recombination losses and lowering the solar current and voltage. Meteors and debris particles impact the solar cell thereby creating damage sites. These sites are unable to produce current and tend to shunt current across the p-n junction causing solar cell voltage loss.

\section{Concluding Remarks}

The performance degradation of the ISS P6 SAWs was determined based on data taken over a 2-year period. Using Isc as the SAW performance parameter, the measured degradation was found to be $0.45 \%$ per year for $2 \mathrm{~B}$ and $0.15 \%$ per year for $4 \mathrm{~B}$. This is well below the expected degradation rate of $0.80 \%$ per year. Based on this preliminary assessment, the P6 solar performance after 2-years on orbit is better than predicted. The pros and cons of the Isc degradation measurement method were discussed and alternative methods were identified. If implemented, these methods could offer improved SAW performance degradation measurements based on operating current or maximum power point current/voltage.

\section{Future Work}

NASA plans to monitor P6 SAW performance degradation and that of subsequent power modules as well, and provide assessment up-dates annually to support ISS operations. To enhance these SAW degradation performance assessments, the ISS program office initiated periodic "full shunt" tests in which the SSU shunts all SAW strings for a selected few minutes of target orbits. These tests, the first of which was conducted in April 2003, will provide high quality data sets to better assess SAW Isc changes over time accounting for all SAW strings.

\section{References}

Delleur, Ann M. and Kerslake, Thomas W., "Electrical Performance of the International Space Station US Photovoltaic Array During Bifacial Illumination," 37th Intersociety Energy Conversion Engineering Conference, paper 20004, Washington, DC, July 28-August 1, 2002.

Fincannon, H. James, NASA Glenn Research Center, Personal Communication, January 2002.

Jannette, Anthony G., et al., "Validation of International Space Station Electrical Performance Model via On-Orbit Telemetry," 37th Intersociety Energy Conversion Engineering Conference, Washington, DC, July 28-August 1, 2002.

Kerslake, Thomas W., and Hoffman, David J., "Performance of the Mir Cooperative Solar Array After 2.5 Years in Orbit," 34th Intersociety Energy Conversion Engineering Conference, SAE 99-012632, Vancouver, British Columbia, Canada, August 1-5, 1999.

Whalen, Kenneth, Boeing-Canoga Park, Personal Communication, October 2002. 
Public reporting burden for this collection of information is estimated to average 1 hour per response, including the time for reviewing instructions, searching existing data sources, gathering and maintaining the data needed, and completing and reviewing the collection of information. Send comments regarding this burden estimate or any other aspect of this collection of information, including suggestions for reducing this burden, to Washington Headquarters Services, Directorate for Information Operations and Reports, 1215 Jefferson Davis Highway, Suite 1204, Arlington, VA 22202-4302, and to the Office of Management and Budget, Paperwork Reduction Project (0704-0188), Washington, DC 20503.

\begin{tabular}{|l|l|l}
\hline 1. AGENCY USE ONLY (Leave blank) & $\begin{array}{c}\text { 2. REPORT DATE } \\
\text { July } 2003\end{array}$ & $\begin{array}{c}\text { 3. REPORT TYPE AND DATES COVERED } \\
\text { Technical Memorandum }\end{array}$
\end{tabular}

4. TITLE AND SUBTITLE

5. FUNDING NUMBERS

On-Orbit Performance Degradation of the International Space Station P6

Photovoltaic Arrays

6. AUTHOR(S)

WBS-22-336-33-01-05

Thomas W. Kerslake and Eric D. Gustafson

7. PERFORMING ORGANIZATION NAME(S) AND ADDRESS(ES)

National Aeronautics and Space Administration

John H. Glenn Research Center at Lewis Field

Cleveland, Ohio 44135-3191

8. PERFORMING ORGANIZATION

REPORT NUMBER

E-14073

9. SPONSORING/MONITORING AGENCY NAME(S) AND ADDRESS(ES)

National Aeronautics and Space Administration

Washington, DC 20546-0001

10. SPONSORING/MONITORING AGENCY REPORT NUMBER

NASA TM-2003-212513

AIAA-2003-5999

\section{SUPPLEMENTARY NOTES}

Prepared for the First International Energy Conversion Engineering Conference cosponsored by the American Institute of Aeronautics and Astronautics (AIAA), the American Society of Mechanical Engineers (ASME), and the Institute of Electrical and Electronics Engineers (IEEE), Portsmouth, Virginia, August 17-21, 2003. Responsible person, Thomas W. Kerslake, organization code 6920, 216-433-5373.

\begin{tabular}{|l|l} 
12a. DISTRIBUTION/AVAILABILITY STATEMENT & 12b. DISTRIBUTION CODE
\end{tabular}

Unclassified - Unlimited

Subject Categories: 18 and 20

Distribution: Nonstandard

Available electronically at http://gltrs.grc.nasa.gov

This publication is available from the NASA Center for AeroSpace Information, 301-621-0390.

13. ABSTRACT (Maximum 200 words)

This paper discusses the on-orbit performance and performance degradation of the International Space Station P6 solar array wings (SAWs) from the period of December 2000 through February 2003. Data selection considerations and data reduction methods are reviewed along with the approach for calculating array performance degradation based on measured string shunt current levels. Measured degradation rates are compared with those predicted by the computational tool "SPACE" and prior degradation rates measured with the same SAW technology on the Mir space station. Initial results show that the measured SAW short-circuit current is degrading 0.2 to 0.5 percent per year. This degradation rate is below the predicted rate of 0.8 percent per year and is well within the \pm 3 percent estimated uncertainty in measured SAW current levels. General contributors to SAW degradation are briefly discussed.

\section{SUBJECT TERMS}

Electric power; Solar arrays; International Space Station; Spacecraft performance 15. NUMBER OF PAGES

\begin{tabular}{|c|c|c|}
\hline $\begin{array}{c}\text { 17. SECURITY CLASSIFICATION } \\
\text { OF REPORT } \\
\text { Unclassified }\end{array}$ & $\begin{array}{c}\text { 18. SECURITY CLASSIFICATION } \\
\text { OF THIS PAGE } \\
\text { Unclassified }\end{array}$ & $\begin{array}{c}\text { 19. SECURITY CLASSIFICATION } \\
\text { OF ABSTRACT } \\
\text { Unclassified }\end{array}$ \\
\hline
\end{tabular}

